\title{
GESTÃO ESTRATÉGICA DE CUSTOS NO FORNECIMENTO DE MATÉRIA- PRIMA PARA A USINA SUCROALCOOLEIRA
}

\author{
STRATEGIC MANAGEMENT OF COSTS IN THE RAW MATERIAL SUPPLY FOR \\ SUGARCANE PLANT
}

Luíza Eid de Mello - luiza.eid@hotmail.com Guilherme Augusto Malagolli - guilherme.malagolli@fatectq.edu.br Faculdade de Tecnologia de Taquaritinga (FATEC) - SP - Brasil

DOI: 10.31510/infa.v15i1.360

\section{RESUMO}

O objetivo central deste estudo é analisar os custos do transporte de matéria-prima no setor sucroalcooleiro. A logística nesse setor age de forma significativa, otimizando os custos e introduzindo a empresa no mercado atual. Para analisar quanto uma empresa gasta anualmente com o transporte, foi aplicado um questionário de 8 questões relacionadas a cana-de-açúcar, os custos e os faturamentos em relação a uma safra de 7 meses. Após ser feita a análise dessas questões, conclui-se que os custos dos indicadores variam de um ano para o outro, devido fatores climáticos, aumento de impostos e aumento do valor do combustível.

Palavras-chave: matéria-prima. setor sucroalcooleiro. custos.

\begin{abstract}
The main objective of this study is to analyze the costs of transportation of raw material in the sugarcane sector. Logistics in this sector acts in a significant way, optimizing costs and introducing the company in the current market. In order to analyze how much a company spends annually with the transportation, a questionnaire of 8 questions related to sugar cane, costs and invoices was applied in relation to a crop of 7 months. After analyzing these questions, it is concluded that the costs of the indicators vary from year to year, due to climatic factors, increase of taxes and increase of the value of the fuel.
\end{abstract}

Keywords: raw material. sugarcane sector. costs.

\section{INTRODUÇÃO}

Uma transportadora para ganhar credibilidade no mercado deve contar com uma logística capaz de integrar e agilizar todo processo de envio de mercadoria. Uma vez que a logística se referindo a pesquisas e publicações científicas, há estudos que se tratam de problemas logísticos como roteirização e dimensionamento de frota de veículo, localização e 
dimensionamento e layout de armazéns de forma a serem executados de forma fracionada (CHING, 2010, p. 1).

Conforme analisado por Ching (2010, p. 10), toda a movimentação interna e externa da empresa é controlada pela logística, desde a chegada da matéria-prima, até a entrega do produto final. Dividindo suas atividades da seguinte forma:

- Atividades primárias: transporte (via ferroviária, rodoviário, aeroviário, marítimo e aquaviário), gestão de estoques e processamento de pedidos.

- Atividades secundárias: armazenagem, manuseio de materiais, embalagem de proteção, programação de produtos e manutenção de informação.

O transporte viabiliza o deslocamento de produtos para satisfação dos consumidores, de forma econômica, está ligado a vários setores de atividades. Produzindo como maiores benefícios a mobilidade e a acessibilidade (PEREIRA, 2013).

$\mathrm{O}$ autor ainda ressalta que a movimentação de um fluxo material tem como principal responsável o transporte, que possui como função transportar o produto do fornecedor até o consumidor.

Houve uma evolução muito grande no transporte de cana-de-açúcar no Brasil após a atuação do Centro de Tecnologia Canavieira (CTC) em parceria com fabricantes de carroceria, sempre visando diminuir os custos se adaptando às mudanças ambientais e tecnológicas (NOVACANA, 2013).

A cana de açúcar está ligada ao desenvolvimento do país, desde a época da colonização vem sofrendo um desenvolvimento agronômico e industrial. Essa grande expansão deve-se a grande valorização do etanol, tendo em vista que o mundo percebeu a necessidade de trocar sua matriz energética, optando por uma fonte de energia mais limpa (GOES; MARRA; SILVA, 2008).

A atividade sucroalcooleira no Brasil envolve números muito expressivos, pois se
trata de uma das atividades de maior importância no âmbito econômico e social do
país. Por ser considerado o maior produtor de cana-de-açúcar do mundo (MARQUES;
ALVES; BORGES, 2006).

Segundo Vian e Marin (2018), a quantidade de cana-de-açúcar a ser transportada por caminhão, varia de acordo com a localização, clima, as frentes de corte e tipos de estradas.

Atualmente o transporte dominante da cana-de-açúcar são os caminhões, variando em caminhões médios que suportam de 8 a 10 toneladas, e os superpesados que suportam de 45 a 50 toneladas (MARQUES; ALVES; BORGES, 2006). 


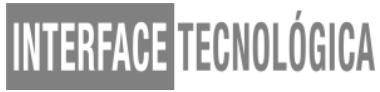

Era utilizado inicialmente o caminhão simples, com apenas um reboque. Logo após, começou a ser utilizado com mais frequência outros tipos de caminhão, como: romeu e julieta, treminhão e rodotrem (NOVOCANA, 2013).

Para Fernandes (1984, apud MARQUES; ALVES; BORGES, 2006) o custo do transporte da cana-de-açúcar tem uma grande relevância no processo. Por isso a grande importância do planejamento, execução e controle desse subsistema, dando resultados positivos ao atingir os acompanhamentos periódicos dos desgastes de pneus, e análise do óleo do motor e câmbio dos veículos.

Caminhões no pátio geram custos, devido a mão de obra e investimentos, além de que pode haver déficit de caminhões circulando, o que acarreta um custo de operários e máquinas paradas. Outro fator é que a cana após ser cortada ou queimada não pode demorar para ser colhida, pois vai perdendo o valor (VIAN E MARIN, 2018).

O objetivo geral desta pesquisa é um estudo sobre a gestão estratégica de custos no fornecimento de matéria-prima para a usina sucroalcooleira.

Os objetivos específicos são aprofundar o conhecimento sobre a gestão estratégica de custos e conhecer o impacto do custo da aquisição da matéria-prima por uma usina sucroalcooleira.

Para isso, foi realizado um referencial teórico sobre transportes para a compreensão dos conceitos relacionados ao transporte de matéria-prima para usinas e a sua ligação com os custos conforme apresentado no item 2 deste artigo.

No item 3, se descreve o método de pesquisa adotado para este artigo, bem como a metodologia do estudo de caso realizado na cidade de Novo Horizonte com a empresa Alfa (nome fictício), onde é especificado os custos totais no transporte sucroalcooleiro.

\section{A LOGÍSTICA DO TRANSPORTE DE CARGAS}

Antigamente, pelo transporte ser realizado através de força física mediante um pequeno raio territorial, as pessoas eram obrigadas a morar próximas das fontes de alimentos, consumindo limitados tipos de produtos. Com o surgimento da logística e a expansão do transporte a variedade de produtos disponíveis para consumo aumentaram (ZUQUETTE; BOZZUTI; COSTA, 2015 apud BALLOU, 2006). 


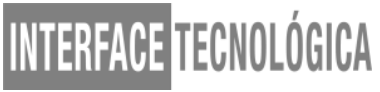

A logística de transporte tem como finalidade atender os mercados consumidores mediante a qualidade de produtos, os prazos para serem entregues, tendo comprometimento no processo (GUERESCHI, 2012).

Segundo Pereira (2013) há cinco tipos diferentes para transporte de carga:

- Rodoviário: aquele feito por caminhões, carretas e treminhões.

- Ferroviário: aquele realizado nas ferrovias por trens, compostos de vagões que são puxados por locomotivas.

- Aquaviário: abrange o modo marítimo e hidroviário

- Marítimo: aquele onde a carga é transportada por embarcações, através de mares e oceanos.

- Hidroviário: aquele transportado em embarcações pelos rios, lagos ou lagoas.

- Aeroviário: aquele realizado por aeronaves.

- Dutoviário: aquele em que os produtos são transportados por meio de dutos.

O transporte de cana para a usina é realizado através do modal rodoviário, porém, geralmente, em condições de vias muito características do setor, como por exemplo, estradas de terra, desniveladas, com ondulações e buracos.

\section{METODOLOGIA DE PESQUISA}

O estudo realizado neste trabalho consistiu em uma pesquisa exploratória e descritiva. O objetivo de uma pesquisa exploratória é compreender um assunto ainda pouco estudado. $\mathrm{O}$ estudo de caso, dentro de uma pesquisa exploratória, refere-se a uma situação, entidade ou conjunto de entidades que têm um mesmo comportamento ou são do mesmo perfil. Não se pode, porém, generalizar as conclusões do estudo de caso, pois são particulares. As conclusões de um estudo de caso geram hipóteses para pesquisas de fenômenos que envolvam um maior contingente de pesquisa (GIL, 2006).

A pesquisa descritiva procura observar, registrar, analisar, classificar e interpretar os fatos ou fenômenos (variáveis), sem que o pesquisador interfira neles ou os manipule. Este tipo de pesquisa tem como objetivo fundamental a descrição das características de determinada população ou fenômeno. 
O objeto de pesquisa é o transporte de cana de açúcar para as usinas e a variável estudada são os custos desta operação.

Como estudo de caso, foi realizada a pesquisa de campo em uma empresa representativa do setor, localizada no município de Novo Horizonte - SP, através de visita técnica e aplicação de questionário semiestruturado.

\section{CARACTERIZAÇÃO DO SETOR SUCROALCOOLEIRO}

O setor sucroalcooleiro apresenta um crescimento muito amplo nos últimos anos, resultando assim no aumento da procura por terras para a plantação de cana de açúcar, e a ampliação de unidades agroindustriais, desenvolvendo automaticamente a região (FAGUNDES; BORGES, 2001).

Conforme Brassolatti (2014), durante todo o período da safra, a quantidade de cana transportada obedece uma média por dia durante toda a safra, conforme a capacidade de moagem da usina.

No Brasil há 60 milhões de hectares destinados a agricultura, 5,86 milhões são utilizados para a plantação de cana de açúcar, o que equivale a 10\% do total da área, tornando assim o Brasil o maior produtor de cana de açúcar do mundo (ALVARENGA; QUEIROZ, 2008).

\section{CUSTOS NO TRANSPORTE DE MATÉRIA-PRIMA PARA A USINA SUCROALCOOLEIRA}

As empresas investem na coordenação dos sistemas de corte e sistemas logísticos que gerenciam o transporte para diminuição de custos (REVISTA LOGÍSTICA, 2016).

Ter uma boa logística se tornou um fato essencial e preocupante nas empresas, pois envolve custos e consequentemente a competitividade desta empresa dentro do mercado, auxiliando também para uma melhor satisfação do cliente (GUERESCHI, 2012).

Os sistemas logísticos utilizados de forma eficaz permitem operar com custos e tempos adequados no abastecimento de cana de açúcar nas usinas, tornando cada vez mais importante a integração transporte e moagem (RANGEL et al., 2008).

Estima-se que no País $95 \%$ da matéria-prima seja transportada pela malha rodoviária de todas as regiões canavieiras, a qual é somada por quatro tipos de segmentos: via de acesso próprio da produtora, vias municipais, estaduais e federais (MARQUES; ALVES; BORGES, 2006). 
Um fator de destaque na logística sucroalcooleira é que a maioria das usinas são instaladas longe de centros urbanos, tendo seus produtores e fornecedores mais próximos, facilitando assim o transporte podendo utilizar caminhões de maiores portes, diminuindo os riscos de acidentes e o custo de frete (RANGEL et al., 2008).

Segundo os estudos da Embrapa, os gastos com transporte equivalem a $12 \%$ de um total de $30 \%$ do custo de corte, carregamento e transporte de uma produção de cana de açúcar (REVISTA LOGÍSTICA, 2016).

Para que não ocorra ociosidade dos caminhões na lavoura, a maioria das usinas investem na comunicação entre a indústria e a lavoura. As operações que acontecem no campo são: desengate, carregamento e engate. $\mathrm{O}$ andamento contínuo dessas operações acarretam ao suprimento da demanda necessária, eliminando paradas por falta de matéria prima causando alto custo de transporte (ALVES, et al., 2011).

Independente do setor que a empresa atua, ela precisa conhecer os seus custos para auxiliar na tomada de decisões, calculando assim o preço de seus serviços. Para uma transportadora, isso se torna ainda mais aflorado, já que se informar dos custos do transporte de carga rodoviário irá auxiliá-lo na formação dos preços de fretes (HIVECLOUD, 2016).

Para Brassolatti (2014), um fator importante nos custos de transporte de cana de açúcar que influi diretamente é a distância das frentes de carregamento (local onde é colhida a cana de açúcar), uma vez que quanto mais longe, maior o gasto de combustível e o desgaste do caminhão. Para amenizar isso, as usinas adotaram uma distância média em um raio de 20 a 30 $\mathrm{km}$.

Para Paranhos (1987, apud MARQUES; ALVES; BORGES, 2006) ao calcular a distância máxima economicamente viável, o número de caminhões utilizados, custos e depredação do caminhão, é de grande relevância levar em consideração o tipo de sistema viário utilizado, se é asfalto, estrada de terra e presença de mata burros.

O transporte de cana-de-açúcar teve uma evolução muito grande, passando dos caminhões toco, romeu e julieta, treminhões para rodotrens. Este é o transporte mais econômico, operando com uma quantidade menor de caminhões e obtendo várias vantagens operacionais (BRASSOLATTI, et al., 2014).

O monitoramento do custo de corte, carregamento e transporte através de sistemas de gerenciamento pode indicar as usinas quais os processos com maior atratividade econômica (BANCHI; LOPES; FERREIRA, 2018).

Segundo Banchi, Lopes e Ferreira (2018), deve ser considerado a utilização de caminhões com maior capacidade de carga diminuindo assim a quantidade de viagens (vezes 
que o caminhão vai para as frentes de carregamento) que são feitas. $\mathrm{O}$ transporte de cana já sofreu evoluções em relação aos caminhões que a transportam.

Figura 1- Tipos de caminhões para transporte de cana

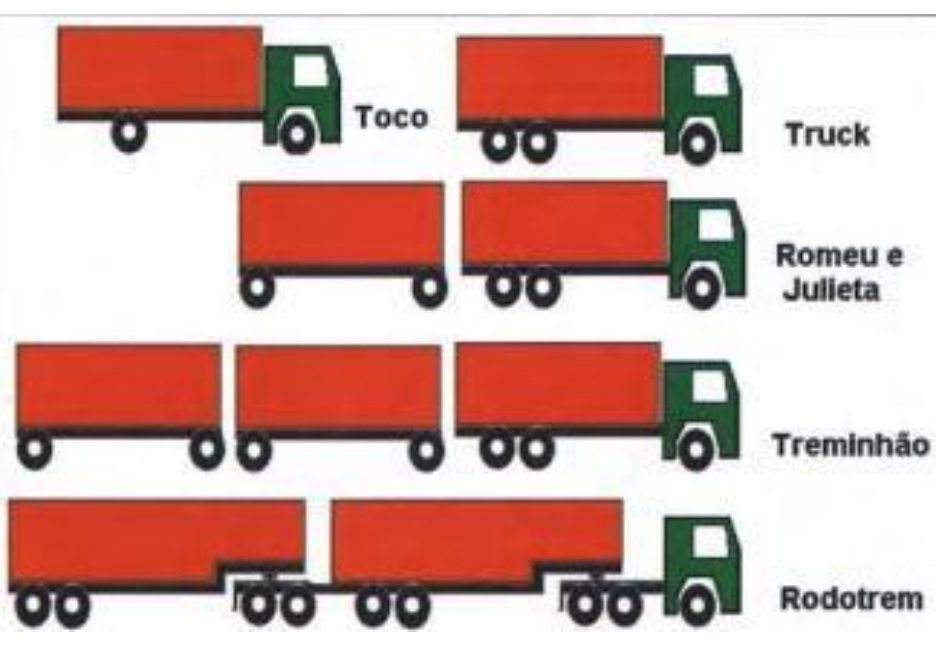

Fonte: Banchi, Lopes e Ferreira (2018)

Destacamos que o custo fixo (depreciação do bem, juros, motoristas e taxas) aumenta proporcionalmente com a quantidade de carga transportada. Mas em compensação, quando avaliados por tonelada transportada $(\mathrm{R} \$ / \mathrm{t})$, cem substancialmente. O mesmo não acontece com o custo variável (combustível, lubrificante, peças, mão de obra, pneus, serviços de terceiros) que seria razoável admitir uma proporcionalidade a carga transportada, já que sua curva de custos por tonelada é inferior ao crescimento da curva por quilometragem (BANCHI; LOPES; FERREIRA, 2018).

O corte, o carregamento e o transporte exigem equipamentos de um custo muito elevado, como por exemplo: colhedoras, tratores e caminhões. Ao planejar a utilização desses equipamentos, a usina não pode se limitar somente a quantificação. Há alguns aspectos que seria viável um gerenciamento, tais como a forma de operá-los, a localização da frente de carregamento e corte e turnos de trabalho (SILVA, 2006).

Segundo Hivecloud (2016), os custos diretamente ligados com o transporte de cargas estão divididos em custos fixos e variáveis.

- Custos fixos: não variam conforme a distância percorrida, ou seja, ele existe mesmo com o veículo parado, sendo calculado mensalmente. Exemplos: salário do motorista, licenciamento e seguro.

- Custos variáveis: variam de acordo com a distância percorrida. Exemplos: peças de manutenção, combustível e lubrificante. 


\section{ESTUDO DE CASO}

\subsection{Características da empresa}

A empresa Alfa (nome fictício), localizada no município de Novo Horizonte - SP, responsável por atuar no transporte de cana-de-açúcar das frentes de corte e carregamento para a usina sucroalcooleira de forma terceirizada.

A mesma, conta com uma frota de 3 caminhões treminhões, 9 funcionários que são distribuídos igualmente para cada veículo, com uma carga horária de 8 horas por dia, trabalhando 7 meses por ano.

\subsection{Análise dos dados}

Após a aplicação do questionário, obteve-se um conjunto de dados que foram analisados e transformados em gráficos de acordo com as questões abordadas.

A ilustração abaixo descreve as porcentagens dos custos de todos os fatores utilizados anualmente pela empresa.

Figura 2: Custos anual da empresa

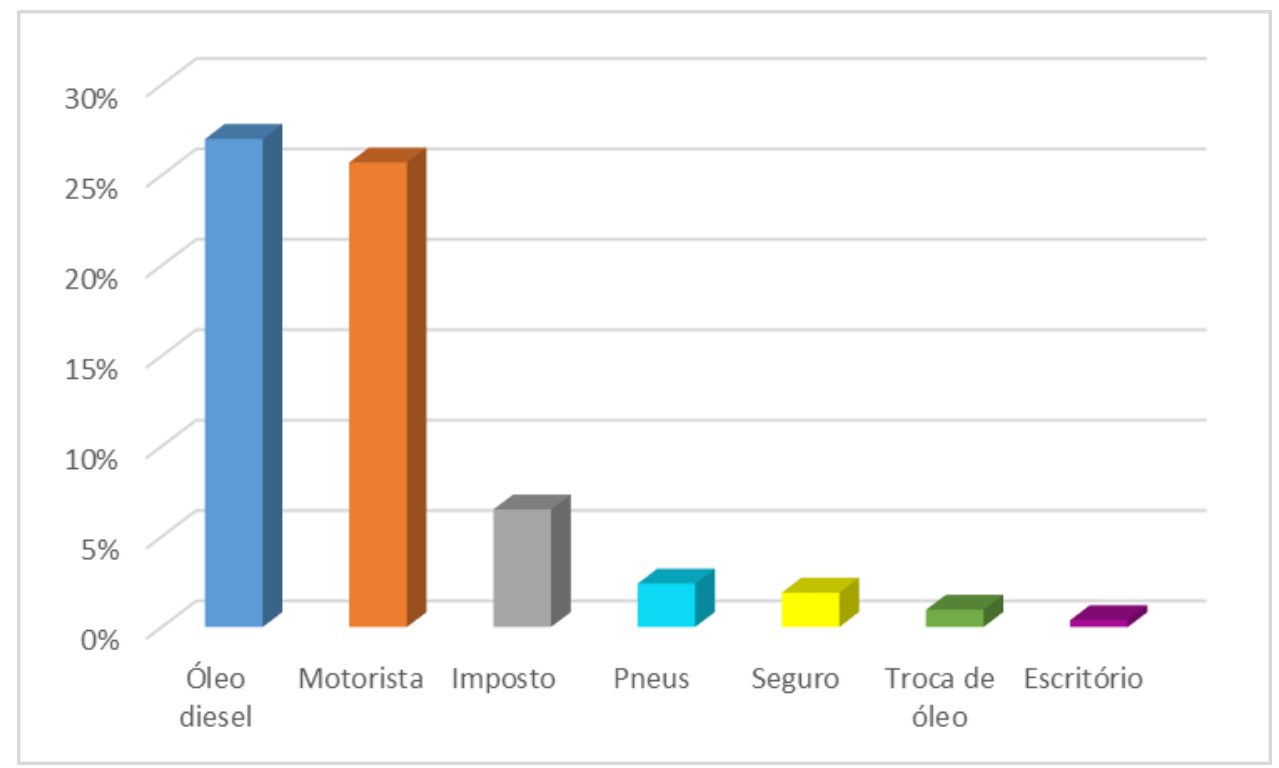

Fonte: elaborada pelos autores (2018) 
Decorrente ao faturamento anual, a empresa gasta o equivalente a 27\% com óleo diesel, $25,7 \%$ com os nove motoristas, $6,5 \%$ dos impostos, $1,9 \%$ dos seguros, $0,95 \%$ da troca de óleo, $2,4 \%$ da troca de pneus e $0,38 \%$ do escritório de contabilidade.

Somando as porcentagens referentes aos fatores de custos, observa-se que a empresa tem um custo percentual de $64,83 \%$ anualmente. Analisando esses parâmetros, conclui-se que a empresa tem um lucro percentual de $35,16 \%$ anualmente.

Através da ilustração, é visível as porcentagens de maiores ênfases no custo dos caminhões: combustível, motoristas e impostos. Porém mesmo observando esses resultados, é meramente impossível diminuir os custos relacionados a esses fatores.

Os caminhões trabalham em um período de 7 meses ao ano, tendo 5 meses de entressafra. Nesse período, os custos caem de forma drástica, tendo somente um custo de manutenção que representa $1,22 \%$.

De um ano para o outro, acontece muitas variações. Um fator que sofre alterações de valor considerável é o preço do óleo diesel, que a cada ano sofre um aumento, interferindo assim no custo total.

Outros fatores acabam influenciando no custo da empresa, fatores climáticos, uma vez que chova muito durante a safra, os caminhões são obrigados a parar de trabalhar, ou se estão nas frentes de carregamento muitas vezes atolam e precisam de ajuda de outros maquinários, gerando assim mais um custo.

O período da safra sofre alterações de ano para ano. Em anos anteriores já houve safras entre 8 meses e meio e 7 meses e meio.

O governo estipula uma depreciação de $25 \%$ por ano para os caminhões conforme a lei 12.788, ou seja, propõem a troca dos mesmos em um período em média de 5 em 5 anos.

\section{CONCLUSÃO}

Após o questionário aplicado na empresa Alfa, no município de Novo Horizonte - SP, observou-se os maiores e menores níveis de custos no transporte de matéria prima para uma usina sucroalcooleira, que apresenta um custo percentual de $64,83 \%$ ao ano.

Dentre os principais resultados obtidos na pesquisa, estão os fatores de maiores custos anuais, que são: óleo diesel, motoristas e os impostos, porém são custos nos quais a empresa não consegue diminuir. 
Foi possível analisar também os custos mínimos da entressafra, que giram em torno de uma porcentagem de $1,22 \%$ relacionado a manutenção e a ociosidades dos caminhões durante um período em média de 5 meses.

A empresa de ano para ano sofre com uma alteração de custos no óleo diesel, no período da safra, que oscila entre 7 e 8 meses anuais, nos fatores climáticos, afetando assim diretamente os lucros obtidos.

A logística apresentada pelas empresas é de extrema importância, uma vez que sua localização longe de centros urbanos, facilita o fluxo dos caminhões e torna mais próximas às frentes de corte e carregamento da matéria-prima, diminuindo assim os gastos com óleo diesel.

\section{REFERÊNCIAS}

ALVARENGA, R. P.; QUEIROZ, T. R. Caracterização dos aspectos e impactos econômicos, sociais e ambientais do setor sucroalcooleiro paulista. Congresso da sociedade brasileira de economia, administração e sociologia rural. 2008. Acesso em: 19 de abril de 2018.

ALVES, E.R. et al. Logística de transporte no setor sucroenergético: perspectivas atuais na melhoria do processo. Acesso em: 19 de abril de 2018.

BANCHI, A.D.; LOPES, J.R.; FERREIRA, V. Composição do custo com corte, carregamento e transporte de cana de açúcar. Disponível em: < http://assiste.com.br/admin/modSite/arquivos/post/1c32aaf414382a6b94c7ceec912fe91f.pdf > Acesso em: 19 de abril de 2018.

BRASSOLATTI, T. F. Z. Estudo de viabilidade da mudança do transporte de cana de açúcar de treminhão para rodotrem. $2^{\circ}$ Seminário Internacional de Integração e Desenvolvimento Regional. 2014. Acesso em: 19 de abril de 2018.

CHING, H. Y.; Gestão de estoques na cadeia de logística integrada: Supply chain. 4. ed. São Paulo: Atlas, 2010.

FAGUNDES, F. N.; BORGES, A. C. G. Relações Transacionais no setor sucroalcooleiro sob o olhar da economia dos custos de transação. Disponível em: < http://www.enanpege.ggf.br/2015/anais/arquivos/4/119.pdf > Acesso em: 18 de abril de 2018.

GIL, A. C. Métodos e técnicas de pesquisa social. São Paulo . Editora Atlas. 2006.

GOES T.; MARRA R.; SILVA G. S; Setor Sucroalcooleiro no Brasil. Situação atual e perspectivas. Embrapa Informação Tecnológica. 2008. Acesso em: 27 de março de 2018.

GUERESCHI, J. S. Logística de transporte: a importância dos custos logísticos. Disponível em: < http://www.unisalesiano.edu.br/biblioteca/monografias/54810.pdf > Acesso em: 19 de abril de 2018. 
HIVECLOUD. Conheça os principais custos do transporte rodoviário de cargas. Disponível em: < https://www.hivecloud.com.br/post/custos-do-transporte-rodoviario-cargas/ $>$ Acesso em: 09 de abril de 2018.

MARQUES, K. M.; ALVES, K. C. M.; BORGES, R. M. A logística de transporte da canade-açúcar como uma especificidade da logística geral aplicada ao setor sucroalcooleiro. Disponível em:

http://intertemas.toledoprudente.edu.br/revista/index.php/Juridica/article/view/462/456

Acesso em: 18 de abril de 2018.

NOVACANA. Como é feito o transporte de cana-de-açúcar no Brasil? Disponível em: < https://www.novacana.com/cana/transporte-da-cana-brasil/ > Acesso em: 27 de março de 2018.

PEREIRA, D. M. et al. Apostila de sistemas de transporte. 2013. Disponível em: < http://www.dtt.ufpr.br/Sistemas/Arquivos/apostila-sistemas-2013.pdf > Acesso em: $27 \mathrm{de}$ março de 2018.

RANGEL, J. J. A. et al. Simulação computacional para análise do frete no transporte de cana-de-açúcar - um estudo de caso no estado do Rio de Janeiro. Revista Eletrônica Sistemas \& Gestão 3 (3) 250-261. 2008. Acesso em: 18 de abril de 2018.

REVISTA LOGÍSTICA; Transporte e logística correspondem a 30\% do custo de produção da cana-de-açúcar. Disponível em: https://www.imam.com.br/logistica/noticias/transportes/2584-transporte-e-logistica-

correspondem-a-30-do-custo-de-producao-da-cana-de-acucar > Acesso em: 09 de abril de 2018.

SILVA, J. E. A. R. Desenvolvimento de um modelo de simulação para auxiliar o gerenciamento de sistemas de corte, carregamento e transporte de cana de açúcar. Disponível em: https://repositorio.ufscar.br/bitstream/handle/ufscar/3478/DissJEARS.pdf?sequence=1\&isAll owed=y > Acesso em: 19 de abril de 2018.

TRANSPORTE LOGÍSTICO; Custos de transporte. Disponível em: < http://transportelogistico1.blogspot.com.br/2012/05/custos-de-transporte_21.html > Acesso em: 09 de abril de 2018.

VIAN, C. E. F.; MARIN F. R. Logística e transporte. Disponível em: < http://www.agencia.cnptia.embrapa.br/gestor/cana-de-

acucar/arvore/CONTAG01_133_22122006154842.html > Acesso em: 27 de março de 2018.

ZUQUETTE, G.; BOZUTTI, D. F.; COSTA M. A. B. Análise dos fatores críticos de sucesso na logística de abastecimento em empresas no setor sucroalcooleiro. XXXV Encontro Nacional de Engenharia de Produção: Perspectivas Globais para a Engenharia de Produção Fortaleza, CE, Brasil, 13 a 16 de outubro de 2015. Acesso em: 09 de abril de 2018. 